\title{
Hypervalent Sulfur Fluorides and the Design of Liquid Crystals
}

\author{
Peer Kirsch* and Matthias Bremer*
}

\begin{abstract}
Hypervalent sulfur fluorides are providing functional materials - such as liquid crystals - with unique physicochemical properties and new geometric structural elements.
\end{abstract}

Keywords: Direct fluorination · Fluorine chemistry · Hypervalent sulfur fluorides · Quantum chemistry · Substituent effects

\section{Introduction}

When the first liquid crystal displays (LCDs) became commercially available in the early 1970s, their key organic functional components were highly polar cyanobiphenyl and cyanophenylcyclohexane derivatives. Later on, starting in the late 1980s and until today, fluorine-substituted liquid crystals have played an ever-increasingly important role in the development of modern high-resolution liquid crystal displays. ${ }^{[1]}$ Because of the unusual combination of high polarity and low polarizability that fluorine imparts to organic molecules, low threshold voltages, fast switching speeds, and - last but not least - the good reliability essential for TV applications could be realized. Thus, the 'classical' polar substituent in liquid crystals, the cyano group, has been completely replaced by either fluorine itself or by fluorine-containing groups.

The reason behind this technology transition is the cyano group's strong tendency to solvate and to mobilize ionic impurities under the influence of an applied electric field. Fluorinated groups in contrast have much weaker affinity to cations, leaving them adsorbed at stationary peripheral materials, such as the polyimide alignment layer. Unfortunately, for some LCD applications, the molecular dipole moment provided by these 'conventional' fluorinated groups turned out to be insufficient, and more polar alternatives moved into focus.

One candidate that had been around since the early 1960s, was the pentafluorosulfanyl $\left(\mathrm{SF}_{5}\right)$ group. As organic derivatives of the chemically very inert gas $\mathrm{SF}_{6}$, the first pentafluorosulfanyl arenes were prepared by W. A. Sheppard at DuPont. ${ }^{[2]}$ Sheppard was able to obtain $m$ - and $p$ nitrophenyl derivatives by oxidative fluorination of the corresponding disulfides using $\mathrm{AgF}_{2}$ (Scheme 1). He prepared and characterized a number of derivatives, and found them to be very stable towards hydrolysis and other typical synthetic transformations, sometimes even exceeding the stability of the trifluoromethyl group.

Because Sheppard's original synthesis furnished only very moderate yields and was not amenable to technical scale-up, further exploration of organic $\mathrm{SF}_{5}$ derivatives lay dormant for nearly four decades. In 1997, the British company F2Chemicals developed a synthesis for $\mathrm{SF}_{5}$-substituted nitroarenes, based on the direct fluorination of the aryl disulfides using elemental fluorine. The sudden commercial availability of $\mathrm{SF}_{5}$ derivatives revived the interest in the field, and allowed a systematic investigation of the $\mathrm{SF}_{5}$ group as a polar terminal group for liquid crystals. ${ }^{[5]}$

Removing the final obstacles for the wider adoption of $\mathrm{SF}_{5}$ into the standard repertoire of 'organic' functional groups, T. Umemoto introduced in 2007 a process relying on chlorine as the oxidant, using potassium fluoride as a non-hazardous fluorine source.

An alternative access to organic $\mathrm{SF}_{5}$ derivatives is the radical addition of $\mathrm{SF}_{5} \mathrm{Cl}$ or $\mathrm{SF}_{5} \mathrm{Br}$ to olefins. This works particularly well with triethylborane as a catalyst (Scheme 2). ${ }^{[6]}$

\section{The Pentafluorosulfanyl Group}

The interest that the $\mathrm{SF}_{5}$ group soon attracted among the liquid crystal community is based on its chemical stability, which is comparable to the trifluoromethyl

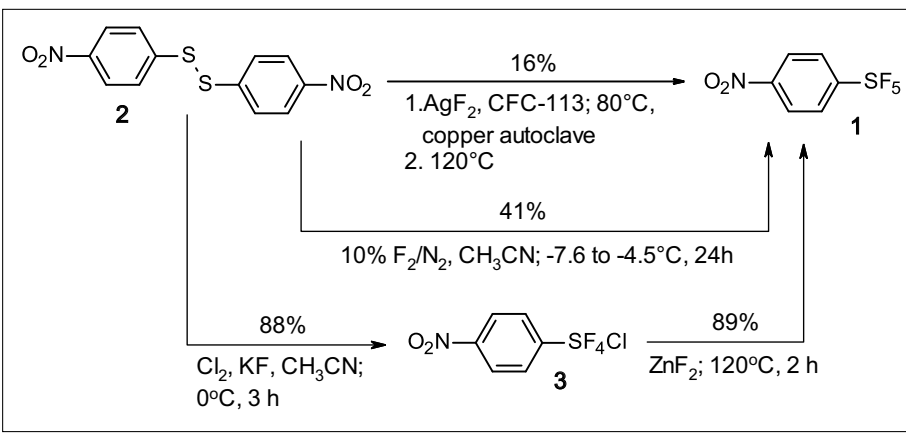

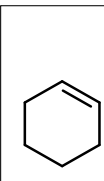

4

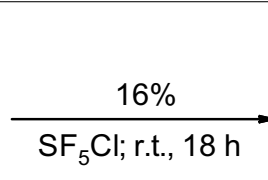<smiles>FC(=S)C1CCCCC1F</smiles>

5
$79 \%$ $\mathrm{KO}$ , $75^{\circ} \mathrm{C}, 15 \mathrm{~min}$

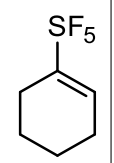

6
Scheme 1. Syntheses of 1 by oxidative fluorination with $\mathrm{AgF}_{2}$, by direct fluorination with $10 \%$ fluorine in nitrogen, ${ }^{[3]}$ and by two-step oxidative fluorination using chlorine together with a fluoride source. ${ }^{[4]}$

Scheme 2. Synthesis of organic $\mathrm{SF}_{5}$ derivatives by radical addition of $\mathrm{SF}_{5} \mathrm{Cl}$ to olefins. 
group, but its group electronegativity is significantly higher, due to the cumulative effect of five fluorine atoms. Thus, $\mathrm{SF}_{5}$ may go by the name of a 'super-trifluoromethyl' group. ${ }^{[7]}$ Whereas trifluoromethyl benzene has a dipole moment of $2.86 \mathrm{D},{ }^{[8]}$ its analogue pentafluorosulfanyl benzene (7) is much more polar with $3.44 \mathrm{D},{ }^{[9]} \mathrm{a}$ fact which moved the $\mathrm{SF}_{5}$ function quickly into the focus of liquid crystal researchers' attention.

\section{Synthesis}

Exploratory synthetic studies (Scheme 3 ) confirmed that aryl-SF $\mathrm{SF}_{5}$ is hydrolytically stable even under harsh acidic or basic conditions, and that it is tolerant towards a variety of transition metal reagents. Interestingly, it was found that 4-bromopentafluorosulfanyl benzene (9) can be smoothly metallo-debrominated with magnesium or tert-butyl lithium in diethyl ether. ${ }^{[10]}$ In contrast, treatment with $n$-butyl lithium in THF at $-78{ }^{\circ} \mathrm{C}$ resulted in immediate, reductive decomposition to a complex mixture of partially defluorinated products $(\mathbf{1 0}, \mathbf{1 1})$.

The usual method for further increasing the dipole moment - and thus the dielectric anisotropy $(\Delta \varepsilon)$ - of liquid crystals is to flank the terminal polar group with one or two ortho-fluorine substituents (Table 1). In the case of terminal trifluoromethyl compounds this approach proved to be very effective, increasing the dielectric anisotropy of $23(\Delta \varepsilon=13.0)$ by 8.5 units to 21.5 for its ortho-difluoro analogue 25 . For $\mathrm{SF}_{5}$ derivatives, Sheppard suggested in 1960 that due to the large steric bulk of the $\mathrm{SF}_{5}$ group it would be extremely difficult to introduce any ortho-substituents. ${ }^{[11]}$ However, J. Thrasher ${ }^{[12]}$ was able to demonstrate in 2001 that not only the oxidation of disulfides works well in the presence of ortho-fluorine, but also that ortho-fluorine activated by a para-nitro group can be easily replaced even by bulky nucleophiles. While Thrasher had used $\mathrm{AgF}_{2}$ as the oxidative fluorination agent, Kirsch and coworkers prepared a variety of ortho-fluorinated, $\mathrm{SF}_{5}$-terminated liquid crystals using selective direct fluorination. ${ }^{[13]}$ The preparative yields were somewhat reduced compared to the non-ortho-fluorinated analogues, but the resulting liquid crystals were obtained in quantities sufficient for a full characterization (Table 1 and Scheme 4).

A further improvement of the mesoscopic profile of $\mathrm{SF}_{5}$-terminated liquid crystals was achieved by insertion of a difluorooxymethylene bridge into the mesogenic core structure (14, Scheme 3$)$. This resulted in a wider nematic phase range, higher clearing temperature and significantly lower rotational viscosity $\left(\gamma_{1}\right)$ than the congener 22 without the fluorinated bridge. ${ }^{[15]}$

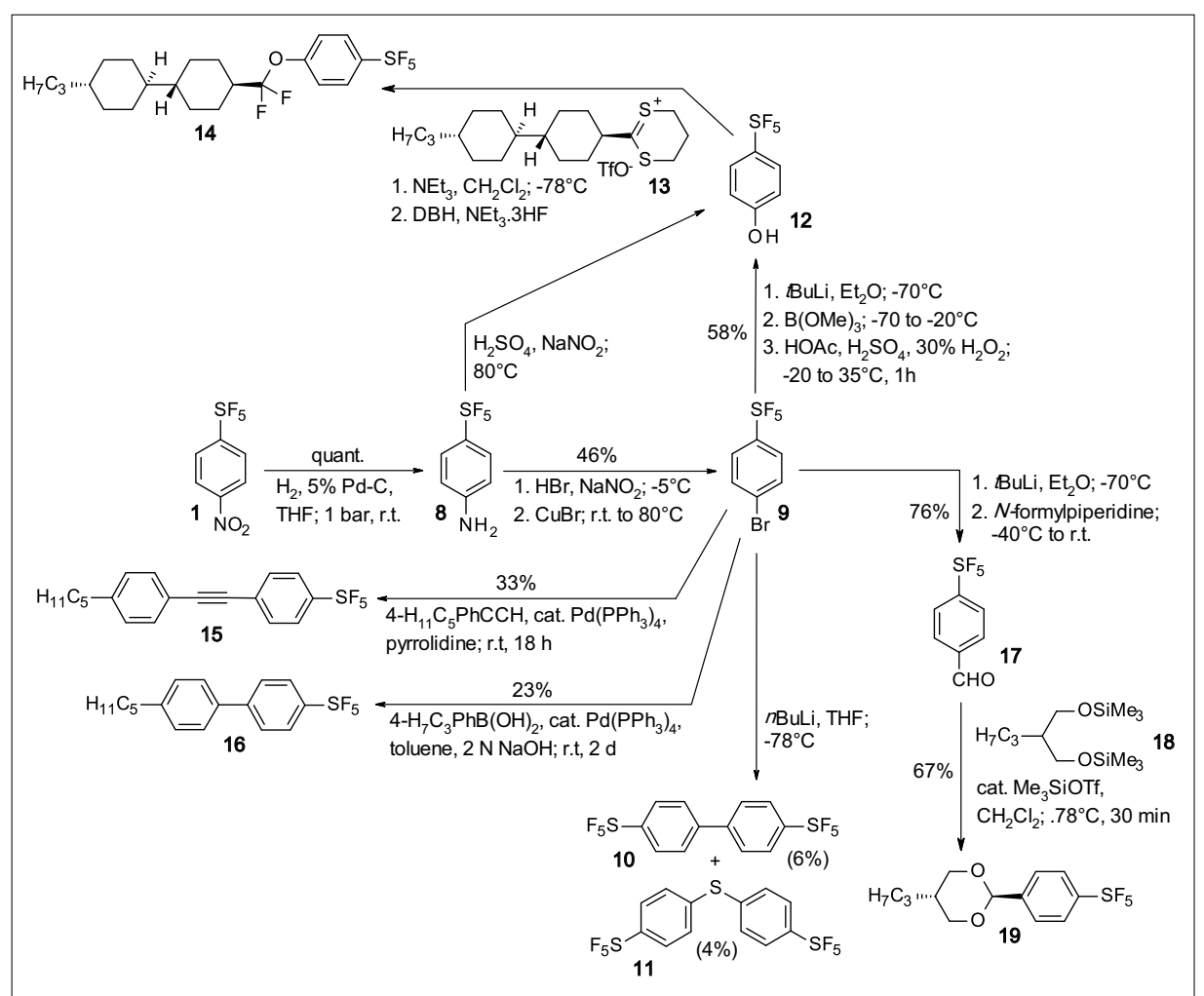

Scheme 3. Synthetic 'tree' starting from 1, with examples of syntheses of several liquid crystals.

Comparison of structurally analogous liquid crystals 20,21 and 22 shows that the cumulative effect of three fluorine substituents in $\mathbf{2 0}$ and $\mathbf{2 1}$ results in a similar dielectric anisotropy. However, the $\mathrm{CF}_{3}$ derivative $\mathbf{2 1}$ shows no real mesophases any more, and the rotational viscosity is much higher than for $\mathbf{2 0}$. Introduction of the $\mathrm{SF}_{5}$ group in material 22 further increases $\Delta \varepsilon$, and the rotational viscosity is higher than for the $\mathrm{CF}_{3}$ analogue 21. The probable reasons for the high rotational viscosities of $\mathbf{2 2}$ and $\mathbf{2 1}$ compared to $\mathbf{2 0}$ are the increase of molecular length from $19.55 \AA$ (20) to $20.55 \AA \mathbf{( 2 1})$ to $21.59 \AA \mathbf{( 2 2})$ and the increasing bulk of the polar group.

Surprisingly, the effect of ortho-fluorination on the dielectric anisotropy of $\mathbf{2 6}$ was much smaller than in the case of the ortho-difluorinated trifluoromethyl analogue 25. A computational analysis shows that the $\mathrm{SF}_{5}$ is responding to the steric pressure from the neighbouring fluorine by spreading the equatorial F-S-F angle. ${ }^{[10]}$ At

Table 1. The physical properties of the liquid crystals 20-26 and 14 in comparison. ${ }^{[14]}$

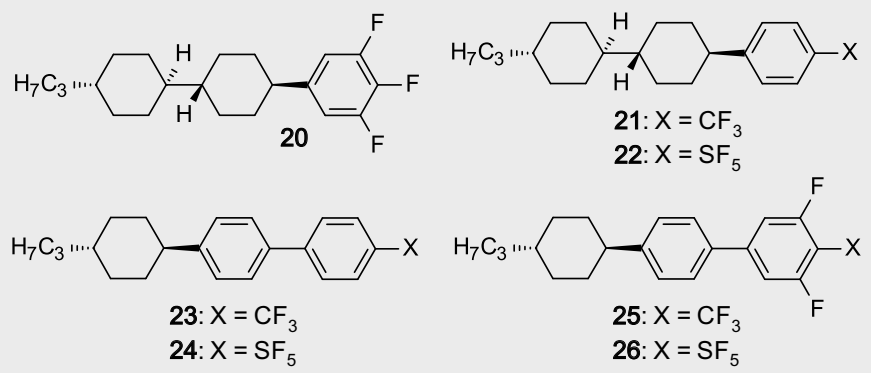

\begin{tabular}{|l|l|r|r|r|r|}
\hline No. & Mesophase Sequence & $\boldsymbol{T}_{\text {NI,virt }}$ & $\Delta \varepsilon_{\text {virt }}$ & $\Delta \boldsymbol{n}_{\text {virt }}$ & $\gamma_{1, \text { virt }}$ \\
\hline $\mathbf{2 0}$ & C 66 N 94.1 I & 74.7 & 9.7 & 0.075 & 160 \\
\hline $\mathbf{2 1}$ & C 133 I & 112.2 & 9.5 & 0.091 & 338 \\
\hline $\mathbf{2 2}$ & C 121 I & 95.5 & 11.7 & 0.093 & 612 \\
\hline $\mathbf{2 3}$ & C 134 I & 109.5 & 13.0 & 0.165 & 279 \\
\hline $\mathbf{2 4}$ & C 109 N (87.8) I & 94.6 & 13.3 & 0.154 & 634 \\
\hline $\mathbf{2 5}$ & C 86 I & 47.1 & 21.5 & 0.149 & n.d. \\
\hline $\mathbf{2 6}$ & C 103 I & 49.6 & 21.4 & 0.132 & n.d. \\
\hline $\mathbf{1 4}$ & C 67 N 116.5 I & 108.2 & 11.8 & 0.080 & 488 \\
\hline
\end{tabular}




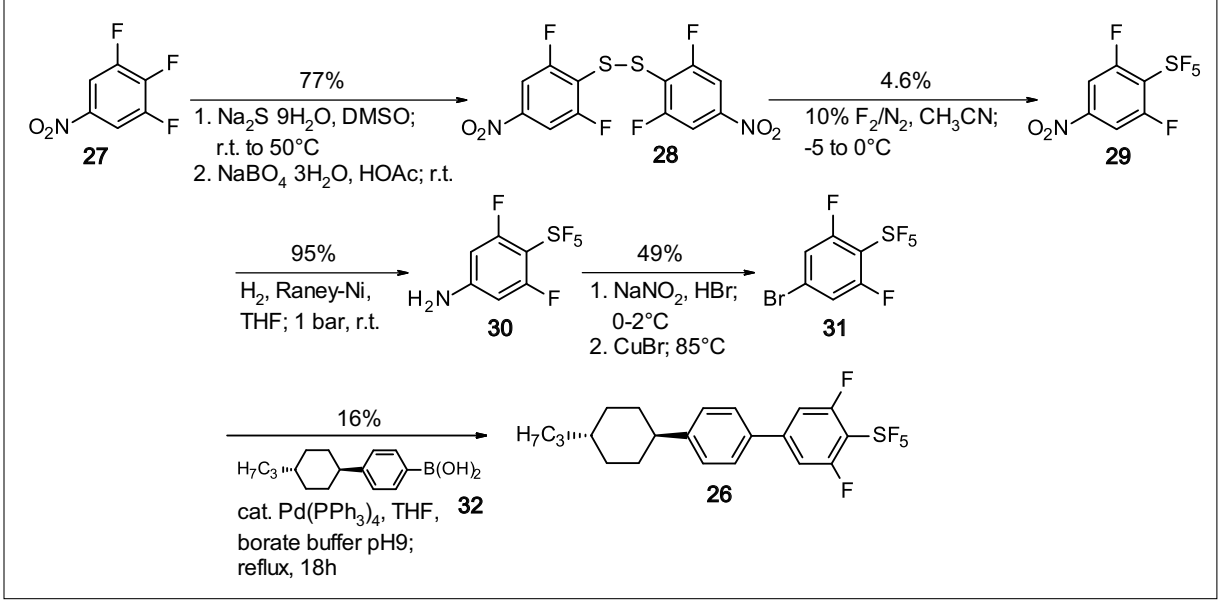

Scheme 4. Synthesis of the ortho-difluorinated $\mathrm{SF}_{5}$-terminated liquid crystal 26. the extrapolated clearing temperature is similar, but the rotational viscosity is by far higher (Scheme 7).

Crystals of sufficient quality could be grown from methylcyclohexane and were subjected to a single crystal X-ray analysis. The molecules crystallize in the triclinic space group $P-1$ with two independent molecules in the asymmetric unit (Fig. 1). ${ }^{[19]}$ To our knowledge, this is the first reported crystal structure of an aryl- $\mathrm{OSF}_{5}$ derivative.

There are no unusual features in the crystal structure apart from the aromatic $\mathrm{OSF}_{5}$-group, which is bent out of the plane of the aromatic rings so that the $\mathrm{C} 1-\mathrm{S} 1$ axis bisects the F1-S1-F5 plane in approximate the same time, the $\mathrm{C}_{\mathrm{ar}}-\mathrm{S}-\mathrm{F}$ angle decreases, creating a local dipole moment which is opposite to the main molecular dipole. Thus, the dipole moments of the orthofluorine substituents are overcompensated by the distortion of the $\mathrm{SF}_{5}$ group, rendering this substitution pattern ineffective for creating a strong dielectric anisotropy.

Alternatively, the $\mathrm{SF}_{5}$ group can be attached to a terminal acetylene ${ }^{[16]}$ or alkenyl unit $^{[17]}$ (Scheme 5), rendering it insensitive to the steric influence of neighboring aromatic substituents. The incorporation of the highly polarizable acetylene link was expected to additionally enhance the molecular dipole moment. The pentafluorosulfanyl ethynyl unit is synthesized starting with the addition of $\mathrm{SF}_{5} \mathrm{Cl}$ or $\mathrm{SF}_{5} \mathrm{Br}$ to the corresponding olefinic or acetylenic precursors followed by elimination of $\mathrm{HCl}$ or $\mathrm{HBr}$, resp., to yield the $\mathrm{SF}_{5}$-substituted products.

Table 2 compares the unsaturated $\mathrm{SF}_{5}$ derivatives with the corresponding $\mathrm{CF}_{3}$ substituted materials. Their properties are quite similar, although the $\mathrm{SF}_{5}$-materials have much higher values for the rotational viscosities $\gamma_{1}$.

\section{The Pentafluorosulfanyloxy Group}

As the $\mathrm{SF}_{5}$ group behaves like a structural analogue of the $\mathrm{CF}_{3}$ group, the $\mathrm{OSF}_{5}$ function can be seen as an enhanced analogue of $\mathrm{OCF}_{3}$, which is widely used as polar group in commercial liquid crystal mixtures. The crucial starting material, 4-bromopentafluorosulfanyloxybenzene $(\mathbf{4 3})^{[18]}$ was coupled with 4-(4'-propylcyclohexyl)benzene boronic acid (32) under Suzuki conditions to furnish $\mathbf{4 4}$ in moderate yield (Scheme 6).

In contrast to its $\mathrm{OCF}_{3}$-analogue 45 , compound $\mathbf{4 4}$ does not exhibit any mesophases and melts at $147^{\circ} \mathrm{C}$ to an isotropic liquid. When compared to the aryl- $\mathrm{OCF}_{3}$ derivative, its polarity is slightly higher,

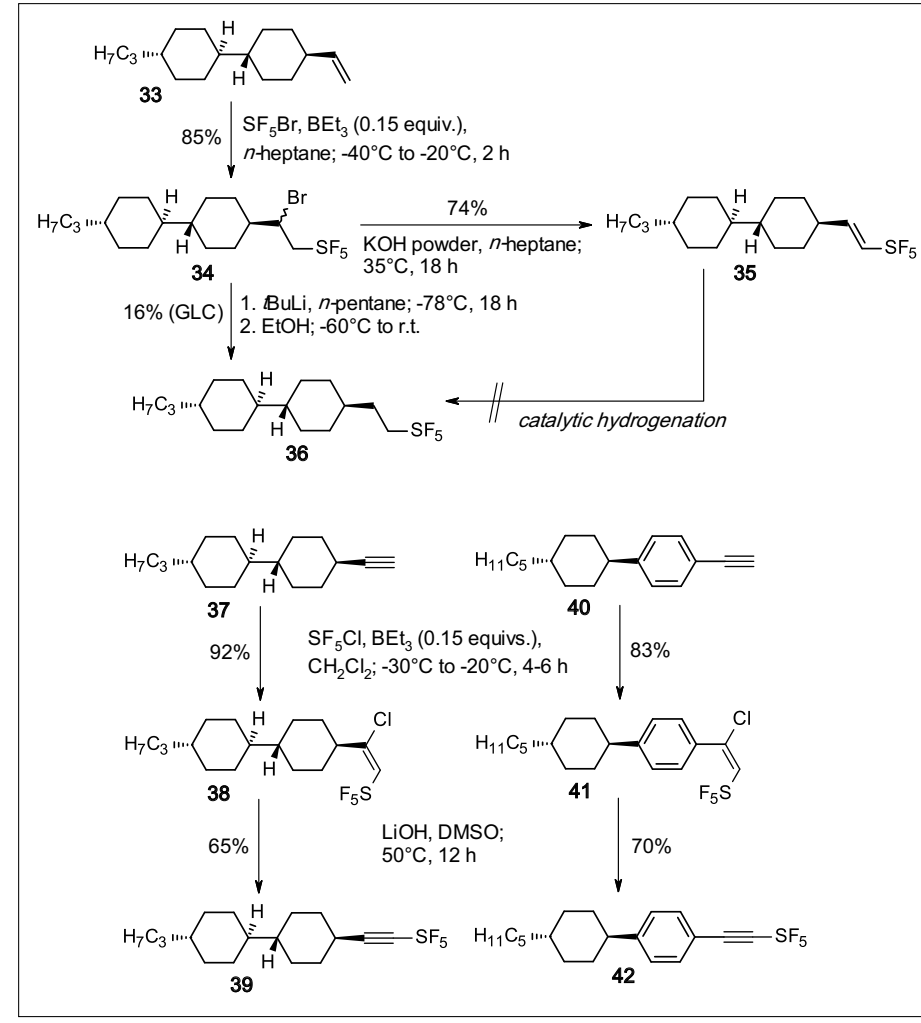

Scheme 5. Synthesis of liquid crystals 39 and 42 containing $\mathrm{SF}_{5}$ alkene and alkyne units.

Table 2. Data for olefinic and acetylenic $\mathrm{SF}_{5}$ materials compared to their $\mathrm{CF}_{3}$ analogues. ${ }^{[14]}$
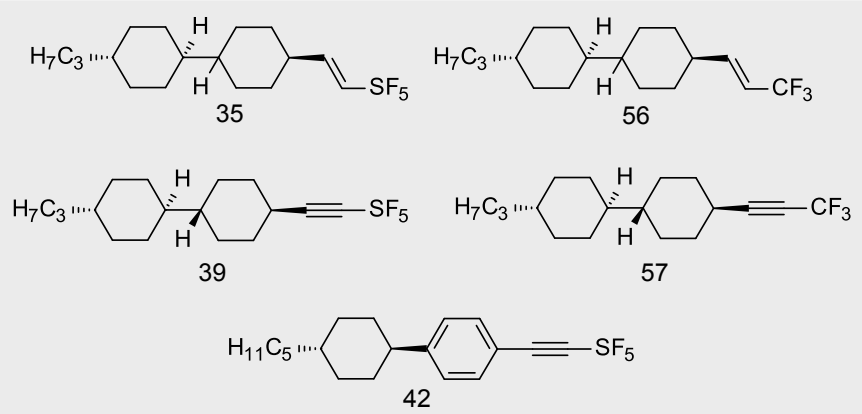

No. Mesophase Sequence

$35 \mathrm{C} 51 \mathrm{~S}_{\mathrm{G}}$ ? 65 I

$\boldsymbol{T}_{\text {NI,virt }}$

8.3

$\Delta \varepsilon_{\text {virt }}$

8.5

10.5

$\Delta \boldsymbol{n}_{\text {virt }}$

0.070

$\gamma_{1, \text { virt }}$

$56 \quad C^{C} \quad 60 \quad S_{\text {B }} 61 \quad$ I

7.9

0.079

n.d.

39 C 49 I

$-28.4$

9.4

0.084

99

57

C $37 \mathrm{~S}_{\text {в }} 52 \mathrm{I}$

$-23.9$

9.7

0.090

236

42 C 38 I

$-44.4$

14.5

0.131 

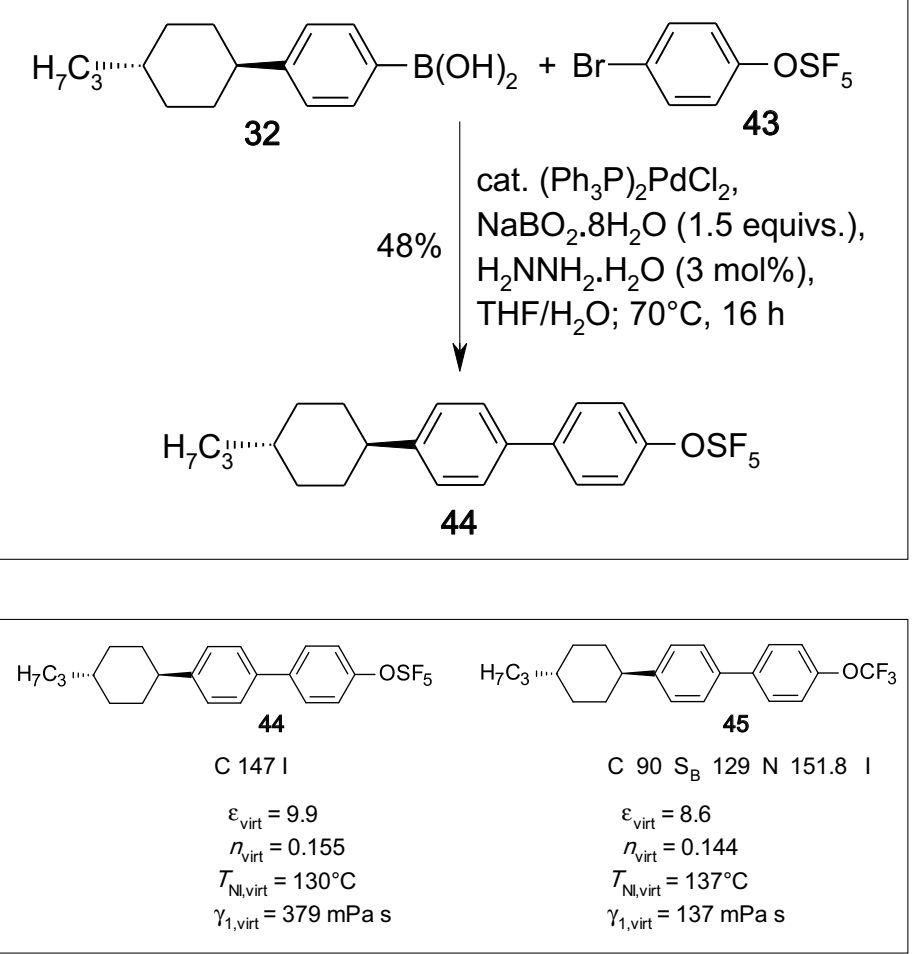

local $\mathrm{C}_{\mathrm{s}}$-symmetry. The geometries in the two independent molecules are very similar and the overall structures have an RMS bond fit of $0.0149 \AA$ and an RMS angle fit of 1.063 degrees. Tables 3 and 4 summarize the important geometrical parameters.

\section{The trans-Trifluoromethyltetrafluo- rosulfanyl Group}

Geometrically, in the $\mathrm{SF}_{5}$ group only one of its five polar sulfur-fluorine bonds $\left(\mathrm{SF}_{\mathrm{ax}}\right)$ is pointing in the direction of the long molecular axis and thus contributing with its static dipole moment to the dielectric anisotropy of the liquid crystal. The equatorial four fluorine substituents $\left(\mathrm{F}_{\mathrm{eq}}\right)$ are forming a 'ring' around the long axis, compensating their dipole moments. As an approach to further increase the group dipole moment of the $\mathrm{SF}_{5}$ function, the axial fluorine was substituted by the more electronegative $\mathrm{CF}_{3}$ group. ${ }^{[20]}$ The resulting trans- $\mathrm{SF}_{4} \mathrm{CF}_{3}$ function was predicted to have a significantly higher dipole moment than the $\mathrm{SF}_{5}$ group. The synthesis starts from the trifluoromethylthioether building block 46 (Scheme 8), which is directly fluorinated with $10 \%$ fluorine in nitrogen. The predominantly generated cis isomer is isomerized with $\mathrm{AlCl}_{3}$ to the geometrically desired, linear trans- $\mathrm{SF}_{4} \mathrm{CF}_{3}$. This functional group exhibits the same chemical stability as the $\mathrm{SF}_{5}$ group and can be converted into the corresponding liquid crystals in an analogous manner.

Surprisingly, the comparison of $\mathbf{5 0}$ with its $\mathrm{SF}_{5}$ analogue $\mathbf{2 4}$ does not show the expected strong increase of $\Delta \varepsilon$ but a sig-
Scheme 7. Liquid crystals 44 and $\mathbf{4 5}$ in comparison. ${ }^{[14]}$

Scheme 6. Synthesis of the $\mathrm{OSF}_{5}$ crystal 44 comparison.

nificant decrease. Analysis of the crystal structure of the intermediate trans-47 and quantum chemical calculations show that the bulky $\mathrm{CF}_{3}$ unit is pushing the ring of four equatorial fluorine substituents away, inducing local dipole moments which terminated liquid molecules of $\mathbf{4 4}$. are opposed to main molecular dipole. [20] Thus, in spite of the strong electron-withdrawing effect of the trans- $\mathrm{SF}_{4} \mathrm{CF}_{3}$ group its influence on the dielectric anisotropy of liquid crystal $\mathbf{5 0}$ is rather limited, and even less than the $\mathrm{SF}_{5}$ group.

\section{The trans-Tetrafluorosulfanylidene Bridge}

The trans $-\mathrm{SF}_{4}$ group can also serve as a linear building block in the mesogenic core structure of liquid crystals. Similarly to the synthesis of trans- $\mathrm{SF}_{4} \mathrm{CF}_{3}$, the synthesis of trans-SF-linked arenes is rather conveniently achieved by direct fluorination of the corresponding diaryl thioether, followed by isomerization with $\mathrm{BF}_{3} \cdot \mathrm{OEt}_{2}$ (Scheme 9). ${ }^{[21]}$ Important is the electronic deactivation of the arene units with electron-withdrawing groups such as nitro or triflate, in order to protect the arene from the electrophilic attack by fluorine. The ar$\mathrm{yl}-\mathrm{SF}_{4}$-aryl unit is much more sensitive toward hydrolysis and reducing agents than $\mathrm{SF}_{5}$ or trans- $\mathrm{SF}_{4} \mathrm{CF}_{3}$. However, if the fluorination/isomerization is the final synthetic step, liquid crystals can be prepared which are stable enough for full characterization.

The trans- $\mathrm{SF}_{4}$-linked liquid crystals 53-55[22] (Table 5) show relatively high melting points and a poor tendency to form

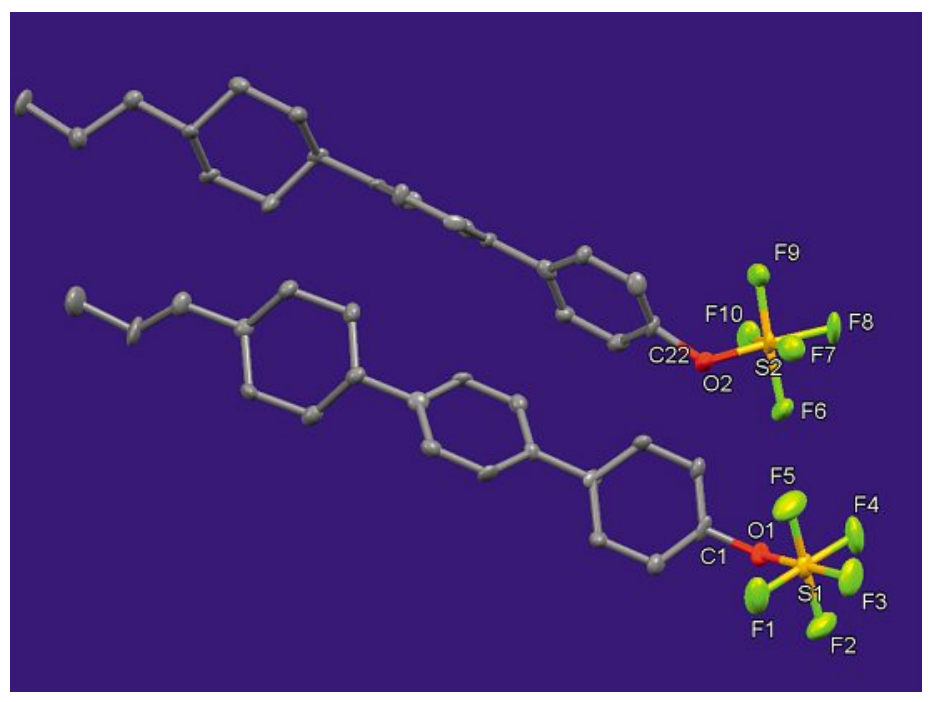

Fig. 1. The aryl-OSF compound $\mathbf{4 4}$ in the solid state (hydrogens not shown, ellipsoids at $50 \%$ probability).

Table 3. Bond distances (in $\AA$ ) at the sulfur atoms in the two crystallographically independent

\begin{tabular}{|l|c|c|c|c|}
\hline Bond & Distance & Bond & Distance & Deviation \\
\hline $\mathrm{S}(1)-\mathrm{F}(1)$ & 1.556 & $\mathrm{~S}(2)-\mathrm{F}(10)$ & 1.561 & -0.005 \\
\hline $\mathrm{S}(1)-\mathrm{F}(2)$ & 1.543 & $\mathrm{~S}(2)-\mathrm{F}(6)$ & 1.546 & -0.004 \\
\hline $\mathrm{S}(1)-\mathrm{F}(3)$ & 1.570 & $\mathrm{~S}(2)-\mathrm{F}(8)$ & 1.580 & -0.011 \\
\hline $\mathrm{S}(1)-\mathrm{F}(4)$ & 1.542 & $\mathrm{~S}(2)-\mathrm{F}(7)$ & 1.558 & -0.016 \\
\hline $\mathrm{S}(1)-\mathrm{F}(5)$ & 1.556 & $\mathrm{~S}(2)-\mathrm{F}(9)$ & 1.570 & -0.014 \\
\hline $\mathrm{S}(1)-\mathrm{O}(1)$ & 1.595 & $\mathrm{~S}(2)-\mathrm{O}(2)$ & 1.597 & -0.002 \\
\hline $\mathrm{O}(1)-\mathrm{C}(1)$ & 1.419 & $\mathrm{O}(2)-\mathrm{C}(22)$ & 1.446 & -0.027 \\
\hline
\end{tabular}


mesophases. Only the ortho-fluoro derivative $\mathbf{5 5}$ exhibits sufficient solubility in the nematic screening host to allow a full characterization.

\section{Physico-chemical Properties}

Although structural elements based on hypervalent sulfur fluorides failed to fulfill their promise as building blocks of nematic liquid crystals (so far!), they are showing some unique features which make them interesting building blocks for other kinds of functional materials or for medicinal chemistry. In particular their combination of extreme polarity (as indicated by the Hammett parameter) and at the same time high lipophilicity renders them ideally suited to convey to functional compounds what has been termed 'polar hydrophobicity' (Fig. 2).[23]

The main cause for the extreme extent of polar hydrophobicity of functional groups such as $\mathrm{SF}_{5}, \mathrm{OSF}_{5}$ and trans $-\mathrm{SF}_{4} \mathrm{CF}_{3}$ are their high volume with very large surface areas but no significant local dipole moments, in comparison to 'classical' polar groups such as cyano or nitro, which are much smaller and have a much more uneven partial charge distribution (Fig. 3).

\section{Molecular Modelling of $\mathrm{PhSF}_{5}$ and PhOSF $_{5}$}

Modern computer programs and quantum chemical methods can deal with molecules of realistic size and are very powerful tools, if an adequate level of theory is employed. [24] Characteristic properties of an LCD, e.g. the threshold voltage (via the dielectric anisotropy $\Delta \varepsilon$ ) and the cell gap (via the birefringence $\Delta n$ ) can be related to the molecular dipole moment and the polarizability of the liquid crystal, and thus be 'modelled'. ${ }^{[25]}$ Especially for novel structural elements, such as the hypervalent sulfur fluorides, a way of predicting important properties is of obvious value. Early calculations on the semi-empirical and Hartree-Fock levels of theory gave very high dipole moments for various $\mathrm{SF}_{5}$ derivatives. Synthetic work was started shortly thereafter, and was published in 1999 together with an X-ray crystal structure of the 1,3-dioxane derivative 19. ${ }^{[10]}$

When applied to liquid crystal 19 (Scheme 3), semi-empirical and ab initio Hartree-Fock calculations gave varying results: the PM3 method was found to severely overestimate the polarity and to give poor agreement of the calculated geometry at the hypervalent sulfur atom with experiment. HF/6-31G(d)-calculations, however, yielded very good geometrical agreement, but also a severe overestimation of the dipole moment.[10]

Table 4. Bond angles (in ${ }^{\circ}$ ) around the sulfur atoms in the two crystallographically independent molecules of 44

\begin{tabular}{|c|c|c|c|c|}
\hline Angle & Angle & Angle & Angle & Deviation \\
\hline $\mathrm{F}(1) \mathrm{S}(1) \mathrm{F}(2)$ & 90.8 & $F(10) S(2) F(6)$ & 90.5 & 0.3 \\
\hline$F(1) S(1) F(3)$ & 88.6 & $F(10) S(2) F(8)$ & 88.1 & 0.5 \\
\hline$F(1) S(1) F(4)$ & 176.3 & $F(10) S(2) F(7)$ & 177.3 & -1.0 \\
\hline$F(1) S(1) F(5)$ & 88.5 & $F(10) S(2) F(9)$ & 89.3 & -0.8 \\
\hline $\mathrm{F}(1) \mathrm{S}(1) \mathrm{O}(1)$ & 93.3 & $F(10) S(2) O(2)$ & 93.6 & -0.4 \\
\hline$F(2) S(1) F(3)$ & 88.9 & $F(6) S(2) F(8)$ & 88.9 & 0.0 \\
\hline$F(2) S(1) F(4)$ & 90.4 & $F(6) S(2) F(7)$ & 89.9 & 0.4 \\
\hline$F(2) S(1) F(5)$ & 176.9 & $F(6) S(2) F(9)$ & 176.7 & 0.2 \\
\hline $\mathrm{F}(2) \mathrm{S}(1) \mathrm{O}(1)$ & 89.6 & $\mathrm{~F}(6) \mathrm{S}(2) \mathrm{O}(2)$ & 88.7 & 0.9 \\
\hline$F(3) S(1) F(4)$ & 87.9 & $F(8) S(2) F(7)$ & 89.2 & -1.3 \\
\hline$F(3) S(1) F(5)$ & 88.1 & $F(8) S(2) F(9)$ & 87.8 & 0.3 \\
\hline $\mathrm{F}(3) \mathrm{S}(1) \mathrm{O}(1)$ & 177.6 & $\mathrm{~F}(8) \mathrm{S}(2) \mathrm{O}(2)$ & 177.0 & 0.6 \\
\hline$F(4) S(1) F(5)$ & 90.1 & $F(7) S(2) F(9)$ & 90.1 & 0.0 \\
\hline $\mathrm{F}(4) \mathrm{S}(1) \mathrm{O}(1)$ & 90.3 & $\mathrm{~F}(7) \mathrm{S}(2) \mathrm{O}(2)$ & 89.1 & 1.2 \\
\hline $\mathrm{F}(5) \mathrm{S}(1) \mathrm{O}(1)$ & 93.5 & $\mathrm{~F}(9) \mathrm{S}(2) \mathrm{O}(2)$ & 94.6 & -1.2 \\
\hline$S(1) O(1) C(1)$ & 123.6 & $\mathrm{~S}(2) \mathrm{O}(2) \mathrm{C}(22)$ & 121.7 & 2.0 \\
\hline
\end{tabular}

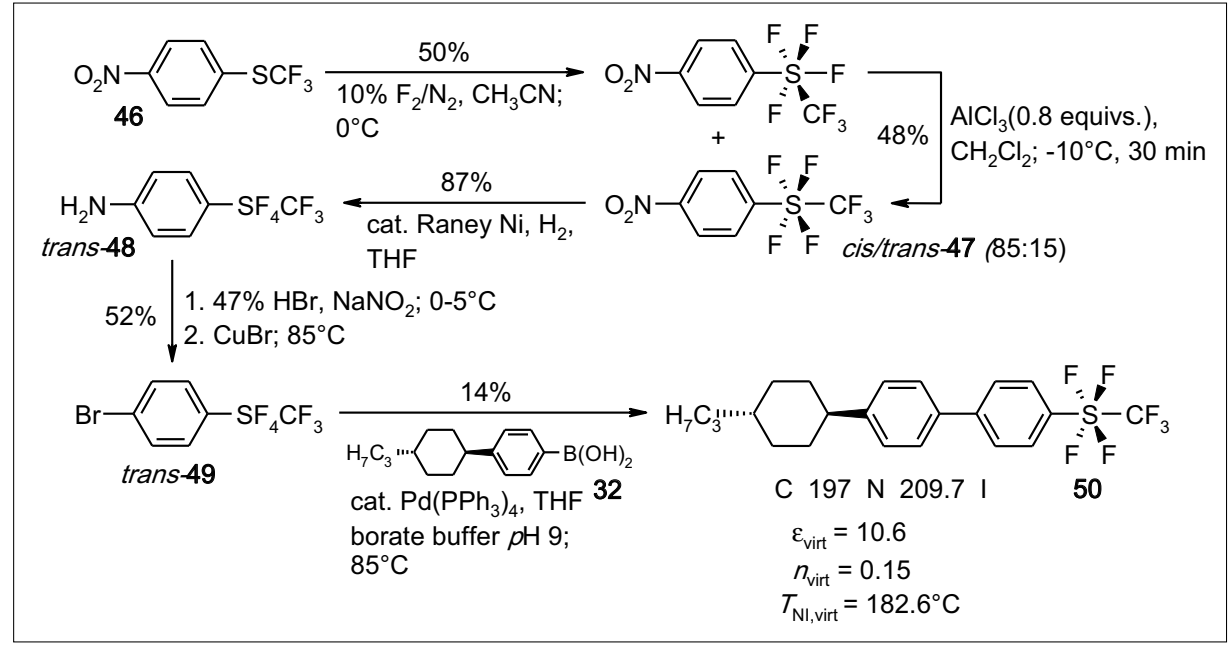

Scheme 8. Synthesis of liquid crystal 50 containing a trans-SF $\mathrm{CF}_{3}$ terminal group.

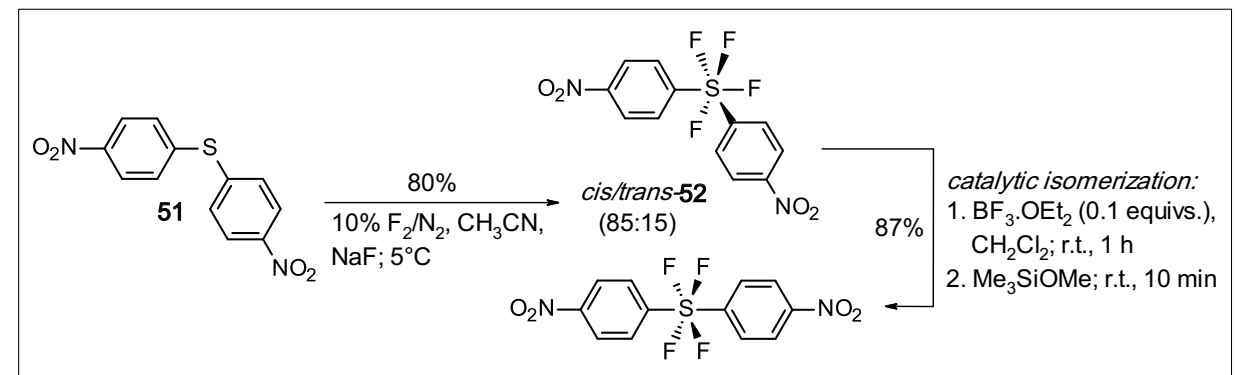

Scheme 9. Synthesis of the trans-SF-linked arene 52.

In a more systematic study, ${ }^{[26]}$ we have compared the calculated structures of the parent compound pentafluorosulfanyl benzene (7) at various levels of theory with the X-ray data of 19. Although an experimental structure of $\mathbf{7}$ has not been determined yet, there are a number of crystal struc- tures containing the $\mathrm{PhSF}_{5}$ moiety in the Cambridge Crystallographic Database. [27] After inspecting those structures, we conclude that $\mathbf{1 9}$ is a representative example and we have used its geometry as a surrogate for comparison. An experimental dipole moment for the parent compound 7 
Table 5. Physical properties of the trans- $\mathrm{SF}_{4}$-linked liquid crystals 53-55. ${ }^{[14]}$

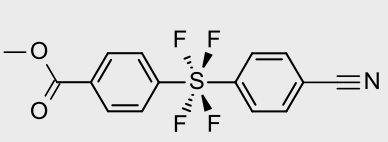

53

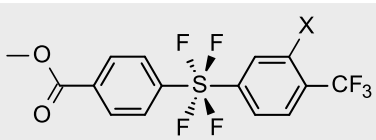

54: $X=H$

55: $X=F$

\begin{tabular}{|l|l|c|c|c|}
\hline No. & Mesophase Sequence & $\boldsymbol{T}_{\text {NI }}$ & $\Delta \varepsilon$ & $\Delta \boldsymbol{n}$ \\
\hline $\mathbf{5 3}$ & C 175 N 179.8 I & n.d. & n.d. & n.d. \\
\hline $\mathbf{5 4}$ & C 146 I & 44.6 & 6.86 & n.d. \\
\hline $\mathbf{5 5}$ & C 136 I & 14.5 & 7.76 & 0.132 \\
\hline
\end{tabular}

like $\mathrm{PhSF}_{5}$. Calculations using the widely employed B3LYP hybrid-DFT functional give large deviations in the $\mathrm{S}-\mathrm{F}$ bond lengths and the chemical shifts. The S-F bond lengths are overestimated by $0.03-$ 0.05 Angstroms, and the molecular dipole moment by up to $0.9 \mathrm{D}$. MP2 ab initio calculations also yield relatively poor agreement, if the basis set is too small (Fig. 4). The more recent M06 density functional fares much better than both B3LYP and MP2, although a relatively large basis appears to be necessary. The 'gold standard'

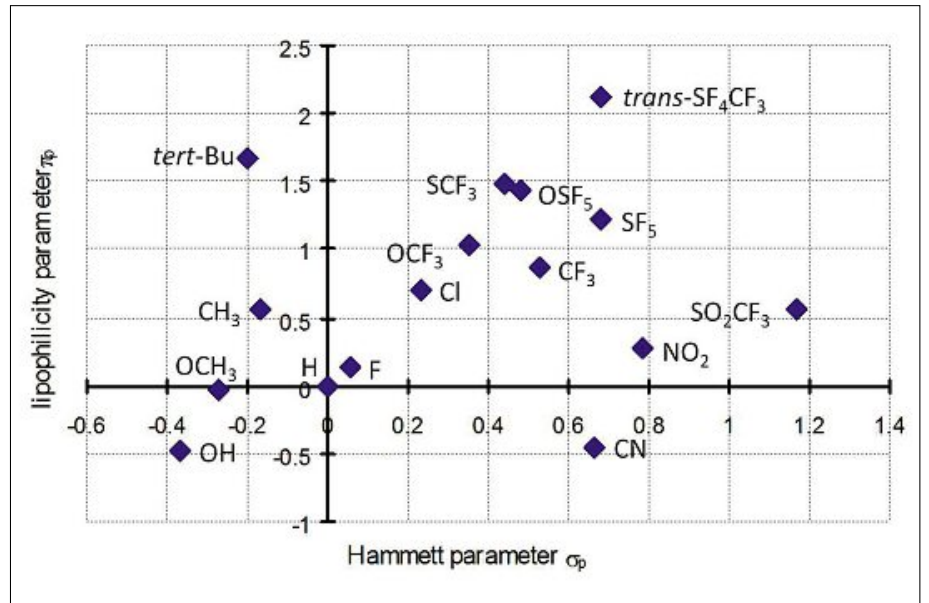

Fig. 2. Plot of the Hammett parameter $\sigma_{\text {para }}$ vs. Hantzsch lipophilicity parameter $\pi_{\text {para }}$ of various common functional groups in comparison. ${ }^{[7]}$ Groups based on hypervalent sulfur fluorides are found exclusively in the upper right quadrant.

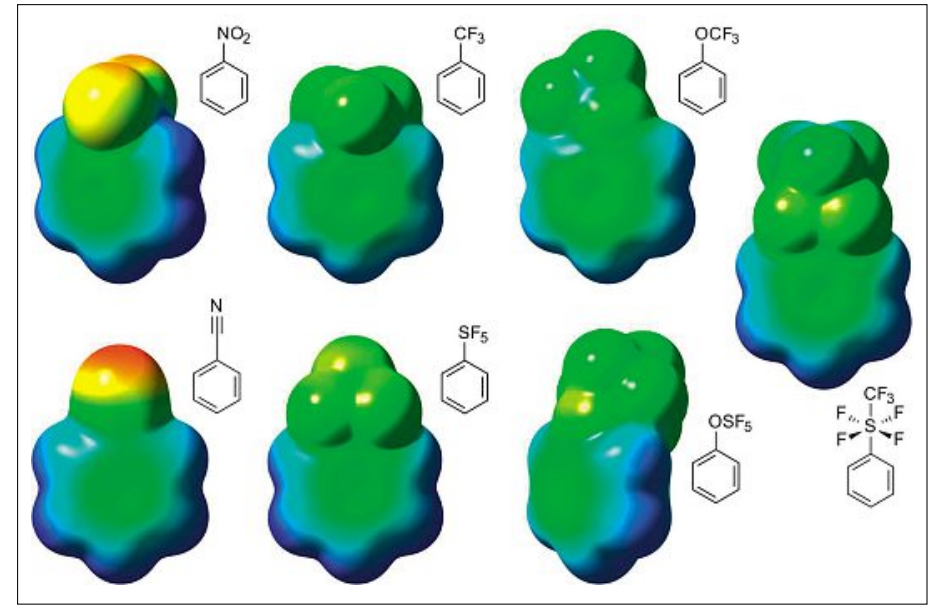

Fig. 3. Electrostatic potential (ESP) surfaces of various carba-/sulfaanalogous pairs of polar benzene derivatives in comparison to 'classical' polar compounds such as benzonitrile and nitrobenzene. The color coding scheme is identical for all ESP surfaces with red corresponding to a partial charge of -0.055 e and blue to +0.030 e. The calculations were carried out at the B3LYP/6-31G(d) level of theory. ${ }^{[24,29]}$ is available ${ }^{[9]}$ and was used as a reference for the calculations. To further assess the quality of the methods employed, we have also calculated ${ }^{19} \mathrm{~F}-\mathrm{NMR}$ chemical shifts of 7 . For ${ }^{13} \mathrm{C}-\mathrm{NMR}$ and ${ }^{11} \mathrm{~B}-\mathrm{NMR}$ this methodology has been very successfully applied to assess the quality of computations on electron deficient carbocations and (carba)boranes, the NMRchemical shifts being a very sensitive probe for the quality of the computed geometries. ${ }^{[28]}$ The key geometrical parameters are the $\mathrm{S}-\mathrm{F}$ distances, one to the axial fluorine atom and one to the four equivalent equatorial fluorine atoms, the ringcarbon-sulfur distance and the angle $\mathrm{F}_{\mathrm{eq}}-\mathrm{S}-\mathrm{F}_{\mathrm{ax}}$ (Table 6).

The agreement of geometries for the HF/DZP calculation and the experiment is surprisingly good and must be fortuitous. After all, the HF-method neglects electron correlation which should be a decisive factor for a molecule
Table 6. Geometrical parameters (distances in $\AA$, angles in ${ }^{\circ}$ ), ${ }^{19} \mathrm{~F}-\mathrm{NMR}$ chemical shifts (in ppm vs. $\mathrm{CFCl}_{3}$ ) and dipole moments (in $D$ ) for 7 on various levels of theory. The abbreviations for the basis sets ${ }^{[2-32]}$ are: $\mathrm{DZP}=6-31 \mathrm{G}(\mathrm{d}), \mathrm{TZP}=6-311+\mathrm{G}(2 \mathrm{~d}, \mathrm{p}), \mathrm{CC}=\mathrm{cc}-\mathrm{pVTZ}$. The experimental geometry refers to the X-ray crystal structure of 19 . Values for the chemical shifts and the dipole moment are those reported in the literature for $\mathrm{PhSF}_{5}$.

\begin{tabular}{|c|c|c|c|c|c|c|}
\hline Level/Parameter & HF/DZP & HF/TZP & B3LYP/DZP & B3LYP/TZP & B3LYP/CC & Expt \\
\hline $\mathrm{SF}_{\mathrm{ax}}$ & 1.576 & 1.558 & 1.623 & 1.616 & 1.608 & 1.579 \\
\hline $\mathrm{SF}_{\mathrm{eq}}$ & 1.583 & 1.566 & 1.631 & 1.628 & 1.620 & 1.583 \\
\hline $\mathrm{CS}$ & 1.801 & 1.800 & 1.825 & 1.828 & 1.831 & 1.807 \\
\hline FSF & 87.5 & 87.7 & 87.6 & 87.5 & 87.7 & 87.8 \\
\hline Shift $_{\mathrm{ax}}$ & 105 & 81 & 140 & 136 & 124 & 84 \\
\hline Shift $_{\mathrm{eq}}$ & 78 & 65 & 88 & 91 & 82 & 62 \\
\hline Dipole & 4.1 & 3.8 & 4.0 & 4.3 & 4.0 & 3.4 \\
\hline Level/Parameter & M06/DZP & M06/CC & MP2/DZP & MP2/CC & $\mathrm{CCSD} / \mathrm{CC}$ & Expt \\
\hline $\mathrm{SF}_{\mathrm{ax}}$ & 1.606 & 1.574 & 1.618 & 1.589 & 1.580 & 1.579 \\
\hline $\mathrm{SF}_{\mathrm{eq}}$ & 1.613 & 1.587 & 1.626 & 1.602 & 1.590 & 1.583 \\
\hline $\mathrm{CS}$ & 1.804 & 1.804 & 1.801 & 1.802 & 1.805 & 1.807 \\
\hline FSF & 87.4 & 88.0 & 87.7 & 88.0 & 88.0 & 87.8 \\
\hline Shift $_{a x}$ & 122 & 103 & 108 & 85 & 95 & 84 \\
\hline Shift $_{\mathrm{eq}}$ & 79 & 71 & 72 & 62 & 65 & 62 \\
\hline Dipole & 4.1 & 3.6 & 4.0 & 3.5 & 3.5 & 3.4 \\
\hline
\end{tabular}




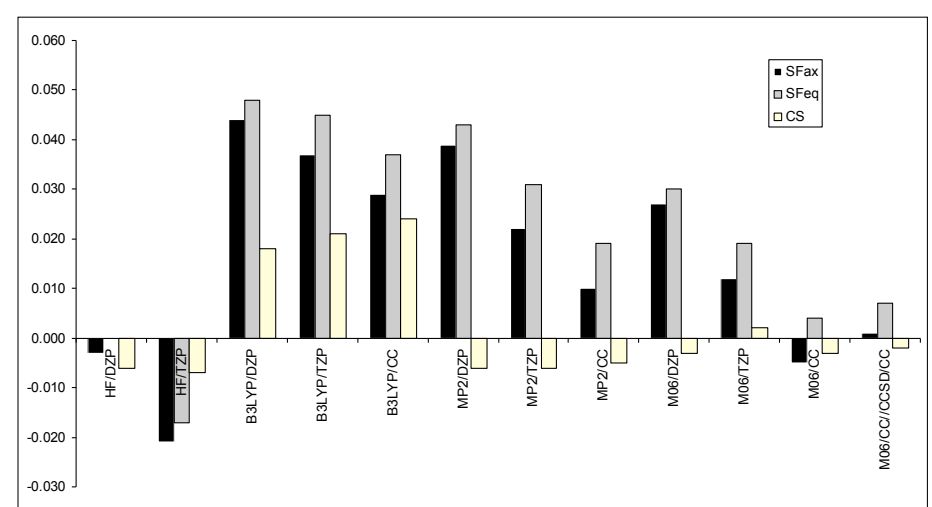

Fig. 4. Deviations of experimental and calculated bond distances (in Å) for $\mathrm{PhSF}_{5}$.

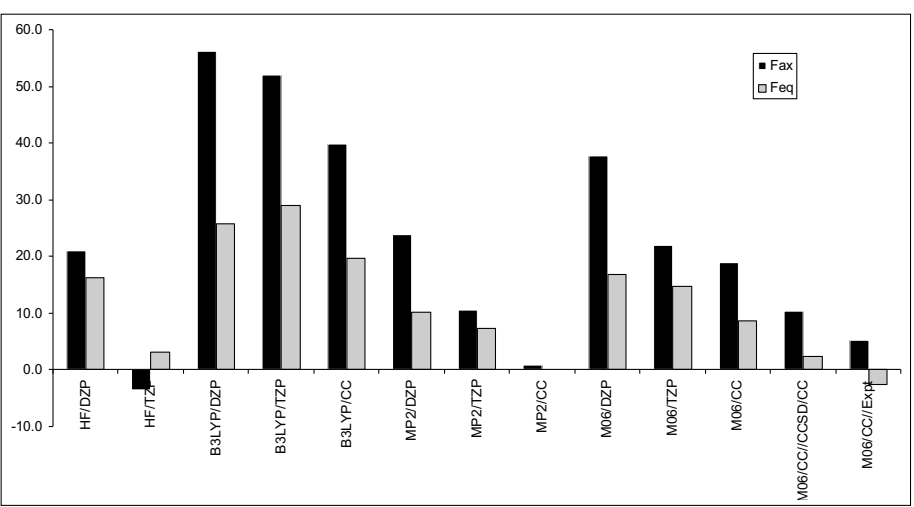

Fig. 5. Deviations of experimental and calculated ${ }^{19} \mathrm{~F}-\mathrm{NMR}$ chemical shifts (in ppm) for $\mathrm{PhSF}_{5}$. Unless indicated by the presence of a double slash '//', the method used for the energy computation and geometry optimization were identical.
CCSD/cc-pVTZ-calculation reproduces the experimental geometries as well as the dipole moment.

The NMR shifts at the MP2 and M06 levels of theory and agree well with experiment if the cc-pVTZ basis is used (Fig. 5). The basis set employed for the calculations has a strong effect on the correct description of both the geometry and the predicted NMR chemical shifts. The cc-pVTZ basis contains two sets of $d$-functions and one set of $f$-functions on sulfur. If these functions are included on sulfur and the basis set on the remaining atoms has only DZP-quality, almost identical results are obtained on the M06 level of theory: (6-31G(d)

basis on $\mathrm{C}, \mathrm{H}, \mathrm{F}$; 6-31G(2df) basis on $\mathrm{S}$ : $\mathrm{S}-\mathrm{F}_{\mathrm{ax}}=1.584 \AA$, $\mathrm{S}-\mathrm{F}=1.592 \AA, \mathrm{C}-\mathrm{S}=1.806$ $\AA$ A, F-S-F $=88.0^{\circ}$, shift $_{\text {ax }}=83.8$ ppm, shift $_{\text {eq }}=56.1$ ppm, dipole $=3.54 \mathrm{D})$.

The prototypical hypervalent compound sulfur hexafluoride, as expected, gives similar results when compared to experimental data, as summarized in Table 7.

Recent calculations on $\mathrm{SF}_{6}$ at the CCSD level of theory, using large bases of augmented quadruple zeta plus polarization quality, give a value for $\mathrm{S}-\mathrm{F}$ of $1.5607 \AA$, again in close agreement with experiment. ${ }^{[34]}$ Although the CCSD-results presented above have benchmark character, the M06-functional together with the cc-pVTZ basis appears to be the method of choice as far as performance and cost are concerned.

The steric flexibility of $\mathrm{PhSF}_{5}$-group has been probed by Hartree-Fock and DFT calculations, but only modest basis sets were employed. We have repeated these calculations at our 'level of choice'

Table 7. S-F-distances (in $\AA$ ) and ${ }^{19} \mathrm{~F}-\mathrm{NMR}$ chemical shifts (in ppm) for sulfur hexafluoride.

\begin{tabular}{|l|c|c|}
\hline Level & S-F & ${ }^{19} \mathbf{F}-\mathbf{N M R}$ \\
\hline B3LYP/CC//B3LYP/CC & 1.588 & 87 \\
\hline M06/CC//M06/CC & 1.567 & 73 \\
\hline M06/CC//CCSD/CC & 1.563 & 67 \\
\hline M06/CC//Expt & 1.562 & 66 \\
\hline MP2/CC//MP2/CC & 1.572 & 57 \\
\hline Expt $^{[33]}$ & $\mathbf{1 . 5 6 2 2 ( 7 )}$ & $\mathbf{5 6}$ \\
\hline
\end{tabular}

M06/CC. The bending energy profile for the 'umbrella' mode of the four equatorial fluorines was calculated together with the corresponding dipole moments. The results are very similar to those reported earlier[10] at the B3LYP/DZP level of theory (Fig. 6).

To conclude this section, Fig. 7 gives a comparison of the M06/CC-calculated structure of the parent compound $\mathrm{PhOSF}_{5}$ and the geometry found in the $\mathrm{X}$-ray crystal structure of $\mathbf{4 4}$ (molecule 1 of the two independent molecules). The agreement is good, but not perfect. The $\mathrm{C}$ (aryl)-O distance is calculated $0.03 \AA$ too short and the S-F distances are on average $0.03 \AA$ too long. The calculated molecular dipole moment for $\mathrm{PhOSF}_{5}$ is $2.93 \mathrm{D}$ compared to $2.39 \mathrm{D}$ calculated at the same level for $\mathrm{PhOCF}_{3}$ (an experimental value for the latter is 2.36 D. ${ }^{[35]}$ Calculations at M06/6$31 \mathrm{G}(\mathrm{d})$ (and 6-311+G(2df) on sulfur) indicate a very flat rotational profile around the $\mathrm{S}-\mathrm{O}$ bond with a barrier of $0.2 \mathrm{kcal} / \mathrm{mol}$, and a higher barrier around the $\mathrm{C}($ aryl $)-\mathrm{O}$ bond of $3.3 \mathrm{kcal} \cdot \mathrm{mol}^{-1}$. The minimum energy structure of $\mathrm{PhOSF}_{5}$ at M06/cc-pVTZ has only $\mathrm{C}_{1}$ symmetry with a dihedral angle $\mathrm{F} 1-\mathrm{S} 1-\mathrm{O} 1-\mathrm{C} 1$ of $6.1^{\circ}$.

\section{Summary and Outlook}

'Sleeping Beauties' for 40 years, functional groups based on hypervalent sulfur

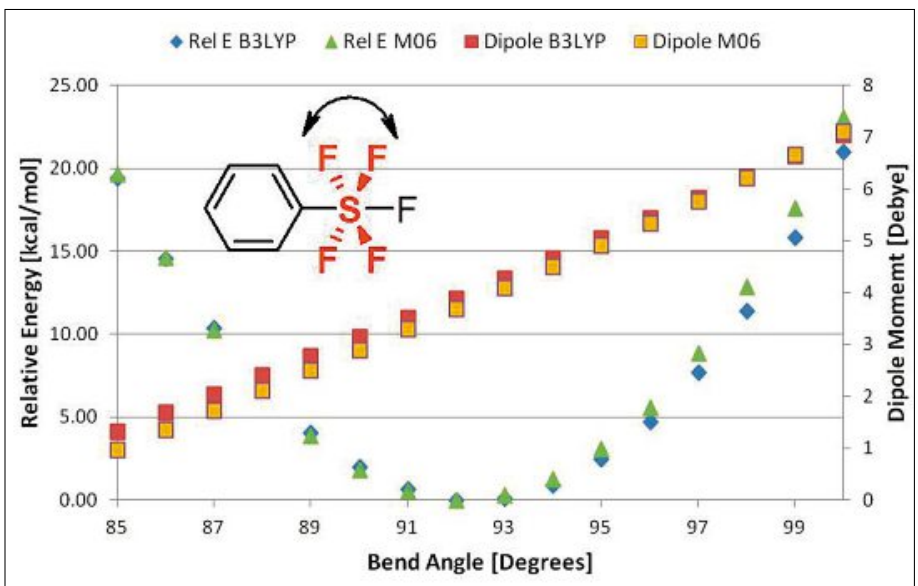

Fig. 6. Energies required for the 'umbrella-like' deformation of $\mathrm{C}_{\mathrm{ar}}-\mathrm{S}-\mathrm{F}_{\text {eq }}$ angles (in ${ }^{\circ}$ ) of 7 , and the resulting dipole moments (in D), calculated at the B3LYP/6-31G(d) and the M06/cc-pVTZ levels of theory.

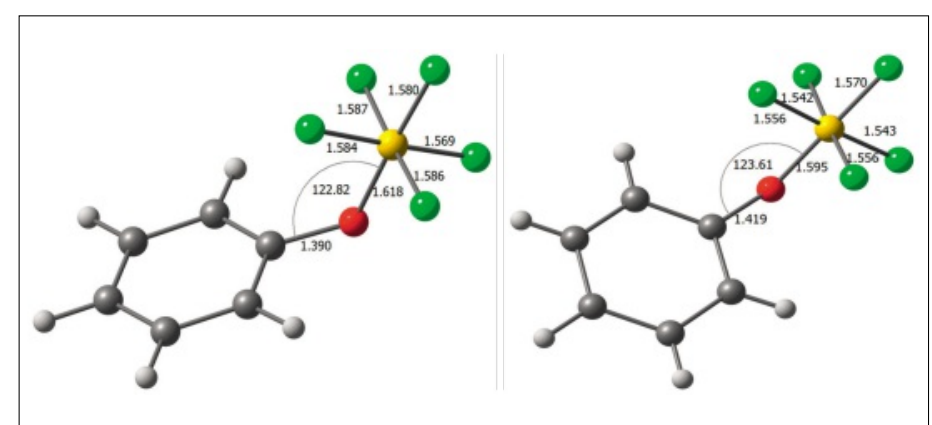

Fig. 7. A comparison of key parameters in the X-ray crystal structure of 44 (right, only the $\mathrm{PhOSF}_{5}$ moiety is shown), and the calculated (M06/CC) geometry of $\mathrm{PhOSF}_{5}$ (left). 
fluorides are now readily available from a synthetic point of view, and they show a chemical stability comparable to 'established' functional groups, such as the trifluoromethyl group. The $\mathrm{SF}_{5}$ and $\mathrm{OSF}_{5}$ functions correspond to their carbon-analogues $\mathrm{CF}_{3}$ and $\mathrm{OCF}_{3}$, but are bigger and more polar with an unusual degree of 'polar hydrophobicity'. Liquid crystals carrying such groups suffer from relatively high rotational viscosity due to their steric bulk. However, hypervalent sulfur groups may be promising new building blocks for pharmaceutical chemistry, and for organic electronics. ${ }^{[36]}$

Received: March 25, 2014

[1] a) M. Bremer, P. Kirsch, M. Klasen-Memmer, K. Tarumi, Angew. Chem. 2013, 125, 9048; Angew. Chem. Int. Ed. 2013, 52, 8880; b) M. Hird, Chem. Soc. Rev. 2007, 36, 2070; c) P. Kirsch, M. Bremer, Angew. Chem. 2000, 112, 4384; d) D. Pauluth, K. Tarumi, J. Mater. Chem. 2004, 14, 1219.

[2] W. A. Sheppard, J. Am. Chem. Soc. 1962, 84, 3064.

[3] a) R. D. Bowden, M. P. Greenhall, J. S. Moillet, J. Thomson, Patent WO 97/05106, 1997; b) R. D. Bowden, P. J. Comina, M. P. Greenhall, B. M. Kariuki, A. Loveday, D. Philp, Tetrahedron 2000, 101, 3399.

[4] a) T. Umemoto, Patent WO 2008/181787, 2008; b) T. Umemoto, L. M. Garrick, N. Saito, Beilstein J. Org. Chem. 2012, 8, 461.

[5] a) P. Kirsch, M. Bremer, M. Heckmeier, K. Tarumi, Angew. Chem. Int. Ed. 1999, 38, 1989; b) J. A. Smith, R. A. DiStasio, Jr., N. A. Hannah, R. W. Winter, T. J. R. Weakley, G. L. Gard, S. B. Rananavare, J. Phys. Chem. B 2004, 108, 19940.

[6] a) F. W. Hoover, D. D. Coffman, J. Org. Chem. 1964, 29, 3567; b) R. W. Winter, G. L. Gard, J. Fluorine Chem. 2004, 125, 549; c) T. A. Sergeeva, W. R. Dolbier, Jr., Org. Lett. 2004, 6, 2417.

[7] P. Kirsch, 'Modern Fluoroorganic Chemistry', 2nd ed., Wiley-VCH, 2013.

[8] J. J. Conradi, N. C. L i, J. Am. Chem. Soc. 1953, 75, 1785.

[9] W. A. Sheppard, J. Am. Chem. Soc. 1962, 84, 3072.

[10] P. Kirsch, M. Bremer, M. Heckmeier, K. Tarumi, Angew. Chem. Int. Ed. 1999, 38, 1989.

[11] W. A. Sheppard, J. Am. Chem. Soc. 1960, 82, 4751.
[12] a) A. M. Sipyagin, C. P. Bateman, Y.-T. Tan, J. S. Thrasher, J. Fluorine Chem. 2001, 112, 287; b) A. M. Sipyagin, S. V. Enshov, S. A. Kashtanov, C. P. Bateman, B. D. Mullen, Y.-T. Tan, J. S. Thrasher, J. Fluorine Chem. 2004, 125, 1305.

[13] P. Kirsch, A. Hahn, Eur. J. Org. Chem. 2005, 3095.

[14] The phase transition temperatures are given in ${ }^{\circ} \mathrm{C}$, the $\gamma_{1}$ values in mPa $\mathrm{s}$. $\mathrm{C}=$ crystalline, $\mathrm{S}_{\mathrm{x}}$ $=$ smectic $\mathrm{X}, \mathrm{N}=$ nematic, $\mathrm{I}=$ isotropic. The 'virtual' parameters $\mathrm{T}_{\mathrm{NI} \text { virt }}, \Delta \varepsilon_{\text {virt }}$ and $\Delta n_{\text {virt }}$ were determined by linear extrapolation from a $10 \%$ w/w solution in the commercially available Merck mixture ZLI-4792 $\left(\mathrm{T}_{\mathrm{NI}}=92.8{ }^{\circ} \mathrm{C}, \Delta \varepsilon=\right.$ $5.3, \Delta n=0.0964)$. The extrapolated values are corrected empirically for differences in the order parameter. For the pure substances the mesophases were identified by optical microscopy, and the phase transition temperatures by differential scanning calorimetry (DSC); numbers in parentheses denote monotropic phase transitions.

[15] P. Kirsch, M. Bremer, A. Taugerbeck, T. Wallmichrath, Angew. Chem. Int. Ed. 2001, 40, 1480.

[16] P. Kirsch, J. T. Binder, E. Lork, G.-V. Röschenthaler, J. Fluorine Chem. 2006, 127, 610.

[17] M. V. Ponomarenko, N. Kalinovich, Y. A. Serguchev, M. Bremer, G.-V. Röschenthaler, J. Fluorine Chem. 2012, 135, 668

[18] a) J. R. Case, R. Price, N. H. Ray, H. L. Roberts, J. Wright, J. Chem. Soc. 1962, 2107; b) J. R. Case, H. L. Roberts, Patent GB 928412, 1963; c) Compound 43 was obtained from Air Products and used as received.

[19] Crystal data: $\mathrm{C}_{21} \mathrm{H}_{25} \mathrm{~F}_{5} \mathrm{OS}, \mathrm{FW}=420.47$; $\mathrm{a}=$ 6.631(2) $\AA, \mathrm{b}=17.117(3) \AA, \mathrm{c}=17.434(4) \AA$, $\alpha=85.46(2)^{\circ}, \beta=85.98(2)^{\circ}, \gamma=88.97(2)^{\circ}, \mathrm{V}$ $=1967.59 \AA^{3}$, space Group P-1 ( $\left.\mathrm{Z}=4\right)$; MoK $0.71073 \AA$, data collection at $100(2) \mathrm{K}, 2.4^{\circ}<$ $\theta<26.4^{\circ}, 7853$ reflections, 3271 reflections $>2 \sigma(\mathrm{I}), 453$ parameters, $\mathrm{R}=0.086$; (Deposit Number at the Cambridge Crystallographic Data Centre: CCDC 992326).

[20] P. Kirsch, A. Hahn, Eur. J. Org. Chem. 2006, 1125.

[21] P. Kirsch, M. Bremer, A. Kirsch, J. Osterodt, J. Am. Chem. Soc. 1999, 121, 11277.

[22] C. Jasper, Merck KGaA, unpublished.

[23] J. C. Biffinger, H. W. Kim, S. G. DiMagno, ChemBioChem 2004, 5, 622.

[24] a) W. J. Hehre, L. Radom, P. v. R. Schleyer, J. A. Pople, 'Ab Initio Molecular Orbital Theory'. Wiley, New York, 1986; b) C. J. Cramer, 'Essentials of Computational Chemistry', 2nd Ed., Wiley, 2004; c) W. Koch, M. C. Holthausen: 'A Chemist's Guide to Density Functional Theory', 2nd Ed., Wiley, 2001; d) F. Jensen, 'Introduction to Computational
Chemistry', Wiley, 2007; e) A. R. Leach, 'Molecular Modelling', Pearson Prentice Hall, 2001

[25] a) M. Bremer, K. Tarumi, Adv. Mater. 1993, 5, 842; b) M. Klasen, M. Bremer, A. Götz, A. Manabe, S. Naemura, K. Tarumi, Jpn. J. Appl. Phys. 1998, 37, L945.

[26] Gaussian 09, Revision B.01, M. J. Frisch, G. W. Trucks, H. B. Schlegel, G. E. Scuseria, M. A. Robb, J. R. Cheeseman, G. Scalmani, V. Barone, B. Mennucci, G. A. Petersson, H. Nakatsuji, M. Caricato, X. Li, H. P. Hratchian, A. F. Izmaylov, J. Bloino, G. Zheng, J. L. Sonnenberg, M. Hada, M. Ehara, K. Toyota, R. Fukuda, J. Hasegawa, M. Ishida, T. Nakajima,Y. Honda, O. Kitao, H. Nakai, T. Vreven, J. A. Montgomery, Jr., J. E. Peralta, F. Ogliaro, M. Bearpark, J. J. Heyd, E. Brothers, K. N. Kudin, V. N. Staroverov, T. Keith, R. Kobayashi, J. Normand, K. Raghavachari, A. Rendell, J. C. Burant, S. S. Iyengar, J. Tomasi, M. Cossi, N. Rega, J. M. Millam, M. Klene, J. E. Knox, J. B. Cross, V. Bakken, C. Adamo, J. Jaramillo, R. Gomperts, R. E. Stratmann, O. Yazyev, A. J. Austin, R. Cammi, C. Pomelli, J. W. Ochterski, R. L. Martin, K. Morokuma, V. G. Zakrzewski, G. A. Voth, P. Salvador, J. J. Dannenberg, S. Dapprich, A. D. Daniels, O. Farkas, J. B. Foresman, J. V. Ortiz, J. Cioslowski, and D. J. Fox, Gaussian, Inc., Wallingford CT, 2010.

[27] F. H. Allen, Acta Crystallogr. 2002, B58, 380; CCSD-codes: GEFZIC, GISVOU, LUGMOQ, OBEJUA, OBEKAH, QAFGOT, QOVYIK, QOVYUW, TIPMEL.

[28] M. E. Harding, J. Gauss, P.v.R. Schleyer, J. Phys. Chem. A 2011, 115, 2340; and references cited therein.

[29] B3LYP: a) A. D. Becke, J. Chem. Phys. 1993, 98, 5648; b) C. Lee, W. Yang, R. G. Parr, Phys. Rev. $B$ 1988, 37, 785; c) S. H. Vosko, L. Wilk, M. Nusair, Can. J. Phys. 1980, 58, 1200; d) P. J. Stephens, F. J. Devlin, C. F. Chabalowski, M. J. Frisch, J. Phys. Chem. 1994, 98, 11623.

[30] M06: Y. Zhao, D. G. Truhlar, Theor. Chem. Acc. 2008, 120, 215

[31] MP2: C. Møller, M. S. Plesset, Phys. Rev. 1934, 46, 0618.

[32] CCSD: 'The beginnings of coupled cluster theory: an eyewitness account', J. Paldus, in 'Theory and Applications of Computational Chemistry', Eds. C.E. Dykstra, G. Frenking, K.S. Kim, G. E. Scuseria, Elsevier, 2005, pp. 115-140.

[33] B. R. Miller, M. Fink, J. Chem. Phys. 1981, 75, 5326.

[34] W. Eisfeld, J. Chem. Phys. 2011, 134, 054303.

[35] W. A. Sheppard, J. Am. Chem. Soc. 1963, 85, 1314.

[36] S. Altomonte, M. Zanda, J. Fluorine Chem. 2012, 143, 57. 